\title{
Correlates of Dual-Method Contraceptive Use: An Analysis of the National Survey of Family Growth (2006-2008)
}

\author{
David L. Eisenberg, Jenifer E. Allsworth, Qiuhong Zhao, and Jeffrey F. Peipert \\ Division of Clinical Research, Department of Obstetrics \& Gynecology, Washington University School of Medicine in St. Louis, \\ 4533 Clayton Ave, Campus Box 8219, St. Louis, MO 63110, USA \\ Correspondence should be addressed to David L. Eisenberg, eisenbergd@wustl.edu
}

Received 14 April 2011; Accepted 27 October 2011

Academic Editor: Jessica M. Sales

Copyright $\odot 2012$ David L. Eisenberg et al. This is an open access article distributed under the Creative Commons Attribution License, which permits unrestricted use, distribution, and reproduction in any medium, provided the original work is properly cited.

Objective. To analyze a nationally representative sample of women for correlates of dual-contraceptive-method use. Materials and Methods. We conducted an analysis of the National Survey of Family Growth, 2006-2008, a cross-sectional survey of reproductiveaged women in the United States. Results. Dual method use was reported by $7.3 \%$ of the 5,178 women in the sample. Correlates of higher rates of dual-contraceptive-method use included age younger than 36 years and nonmarried marital status. Lower rates of dual method use were observed for women with less than a high-school education and women without consistent health insurance in the past year. Compared to women using oral contraceptives, use of the contraceptive injection or long-acting reversible contraception was associated with lower dual-method use. Conclusions. The overall rate of dual-method use in the USA is low. Future interventions to promote dual method use should target high-risk groups with modifiable risk factors.

\section{Introduction}

Sexually transmitted infections (STIs) and unintended pregnancy are important and costly public health issues. The United States has an estimated incidence of 19 million cases of STIs each year which incurs $\$ 15.9$ billion in cost to the health care system $[1,2]$ and unintended pregnancy rates continue to hover at nearly $50 \%$ [3]. One proposed strategy to reduce the risks of unintended pregnancy and STI is the promotion of dual-contraceptive-method use. Dual-method protection includes use of a highly effective pregnancy prevention in conjunction with a barrier (e.g., male condom). The male condom is the most commonly used method of sexually transmitted infection (STI) prevention, whereas the oral contraceptive pill and female sterilization are the most common methods of pregnancy prevention in the USA [4].

The burden of unintended pregnancy and STIs is greater among younger and economically disadvantaged men and women $[3,5]$. While nearly all women report having used birth control and most have used a condom [4], dualmethod use is relatively uncommon. An analysis of the Youth Risk Behavior Surveillance System (YRBS) noted 6.6\% of young women using oral contraceptives also used a condom at last intercourse [6]. According to another study of the YRBS, use of dual-contraceptive methods increased from $3.2 \%$ in 1991 to $7.2 \%$ in 2001 [7]. A more recent publication reviewing data from the National Longitudinal Study of Adolescent Health noted 14-25\% of participants report using dual methods at last intercourse [8].

Most of the previous research focused on adolescents or other populations who carry greater risk of both unintended pregnancy and STI acquisition than the general population. Therefore, we sought to evaluate correlates of dual-method use in a national sample of reproductive-aged women.

\section{Materials and Methods}

We examined data from the 2006-2008 National Survey of Family Growth (NSFG). The NSFG is a cross-sectional survey conducted by the National Center for Health Statistics (NCHS) at the Centers for Disease Control and Prevention and is a survey of family life, marriage and divorce, pregnancy, infertility, use of contraception, and men's and 
TABLE 1: Contraceptive methods used in the last intercourse in past 12 months by nonpregnant females aged $15-44$ years, $N=5178$.

\begin{tabular}{|c|c|c|c|}
\hline Method & $N(\%)^{\dagger}$ & Dual & Single \\
\hline \multicolumn{4}{|l|}{ Any method of contraception } \\
\hline Yes, dual & $448(7.3)$ & & \\
\hline Yes, single & $3341(68.0)$ & & \\
\hline No & $1389(24.7)$ & & \\
\hline \multicolumn{4}{|l|}{ Type of contraceptive method } \\
\hline Nonbarrier methods* & $2694(55.7)$ & $448(13.1)$ & $2246(86.9)$ \\
\hline Pills & $1125(22.3)$ & $280(21.7)$ & $845(78.3)$ \\
\hline Sterilization/partner sterilization & $1004(24.1)$ & $78(4.4)$ & $926(95.6)$ \\
\hline Injectables (Lunelle/Depo-Provera) & $211(2.8)$ & $47(16.7)$ & $164(83.3)$ \\
\hline LARC & $229(4.6)$ & $16(3.3)$ & $213(96.7)$ \\
\hline Patch & $55(0.6)$ & $7(16.0)$ & $48(84.0)$ \\
\hline Ring & $100(2.1)$ & $22(32.6)$ & $78(67.4)$ \\
\hline Barrier methods & $1543(26.8)$ & $448(27.1)$ & $1095(72.9)$ \\
\hline
\end{tabular}

${ }^{*}$ Individual methods do not sum to $\%$ of Nonbarrier methods as respondents may have reported $>1$ Nonbarrier method at last intercourse.

† Weighted percent.

women's health $[9,10]$. The survey is a national probability sample of individuals living in households and oversamples Blacks, Hispanics, teens, and females. The NSFG was conducted from 2006 to 2010 with 110 areas (primary sampling units) selected. Each year a nationally representative subsample of areas was interviewed. Interviews were conducted by the University of Michigan's Institute for Social Research by trained female professional interviewers in the homes of participants using computer-assisted personal interviewing. Interviews lasted on average 80 minutes.

There were 7,356 women between the ages of 15 and 44 years of age interviewed between July 2006 and December 2008. Our analysis included 5,178 women who represent the experiences of approximately 44.5 million women in the United States. We excluded women who were currently pregnant, have had a hysterectomy, had no sexual partners, or reported only female sex partners and therefore not at risk of unintended pregnancy (see Figure 1). We determined current contraceptive method based on respondents' answers to a single question regarding "contraception method used at last intercourse in the past 12 months [11]". Respondents could provide up to four methods in response to this question allowing for estimation of dual-method use.

We calculated the prevalence of dual-method contraceptive use and evaluated demographic and reproductive characteristics that might be associated with dual-method use. Potential predictors of dual-method use included age group (15-20, 21-25, 26-30, 31-35, 36-40, 41-44 years), gravidity, marital status (married, living with partner, widowed/divorced/separated, never married), race (black, white, other), Hispanic ethnicity, highest level of education (less than high school, high school, some college, or college graduate), continuous insurance coverage for all of the prior 12 months, and number of lifetime and past year sexual partners.

In order to focus on correlates of dual-method use we used all respondents who did not report dual-method use

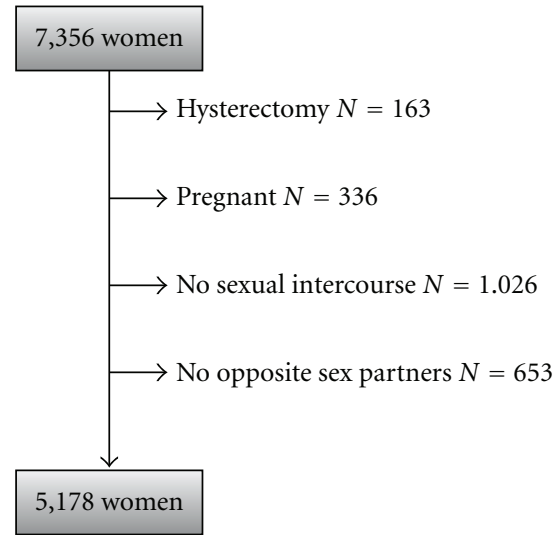

FIgure 1: National Survey of Family Growth (2006-2008) Analytic Sample.

(including single-method users and respondents using no method) as the referent. After evaluating univariate associations using logistic regression, we used a multivariable logistic regression model to assess independent predictors of dual-method use. Our model included the factors found to be associated with dual-method use in the univariate analysis. Reference groups for the multivariable regression were chosen by lowest rate of dual-method use, by clinical judgment or the category with the largest number of respondents.

For our examination of the association between primary method of contraception and dual-method use, we compared dual-method use to single-method use and excluded those participants not using a primary contraceptive method ( $n=1,389)$ or using barrier only method $(n=1095)$, as these women were not eligible for the outcome of interest. "Pill users" included combination and progestin-only oral contraceptives. Users of the transdermal contraceptive patch 
TABLE 2: Summary of participants' characteristics by number of methods used.

\begin{tabular}{|c|c|c|c|c|c|}
\hline & $\begin{array}{l}\text { All non-pregnant women } \\
15-44 \text { years }(N=5178)\end{array}$ & $\begin{array}{c}\text { Dual } \\
(N=448)\end{array}$ & $\begin{array}{c}\text { Single } \\
(N=3341)\end{array}$ & $\begin{array}{c}\text { None } \\
(N=1389)\end{array}$ & $P$ value \\
\hline Age & & & & & $<0.0001$ \\
\hline $15-20$ & $731(11.7)$ & $134(22.8)$ & $438(56.9)$ & $159(20.3)$ & \\
\hline $21-25$ & $976(16.6)$ & $124(12.0)$ & $595(63.4)$ & $257(24.6)$ & \\
\hline $26-30$ & $1114(18.4)$ & $79(5.1)$ & 735 (65.9) & $300(28.9)$ & \\
\hline $31-35$ & $923(18.5)$ & $62(5.2)$ & $598(67.5)$ & $263(27.2)$ & \\
\hline $36-40$ & $853(19.5)$ & $32(1.8)$ & $565(73.1)$ & $256(25.1)$ & \\
\hline $41-44$ & $581(15.2)$ & $17(2.3)$ & $410(77.9)$ & $154(19.8)$ & \\
\hline Race & & & & & $<0.0001$ \\
\hline Black & $1111(15.1)$ & $122(9.4)$ & $662(61.6)$ & $327(29.0)$ & \\
\hline White & 3499 (73.6) & $301(7.4)$ & $2320(69.8)$ & $878(22.7)$ & \\
\hline Others & $568(11.3)$ & $25(3.3)$ & $359(64.5)$ & $184(32.2)$ & \\
\hline Ethnicity & & & & & 0.0049 \\
\hline Hispanic & $1124(16.5)$ & $63(4.2)$ & $724(66.1)$ & 337 (29.7) & \\
\hline Non Hispanic & $4054(83.5)$ & $385(7.9)$ & $2617(68.4)$ & $1052(23.8)$ & \\
\hline Education & & & & & 0.0003 \\
\hline Less than HS & $1088(17.1)$ & $96(6.7)$ & $672(61.1)$ & $320(32.2)$ & \\
\hline High School & $1388(25.8)$ & $116(7.2)$ & $860(67.0)$ & $412(25.9)$ & \\
\hline Some College & $1123(20.9)$ & $125(12)$ & $724(66.5)$ & $274(21.5)$ & \\
\hline College Graduate & $1579(36.2)$ & $111(4.9)$ & 1085 (72.9) & $383(22.2)$ & \\
\hline Marital Status & & & & & $<0.0001$ \\
\hline Married & $2181(53.3)$ & $47(1.6)$ & $1461(72.4)$ & $673(26.0)$ & \\
\hline Living with Partner & $693(13.2)$ & $37(6.1)$ & $448(64.4)$ & $208(29.5)$ & \\
\hline Widowed/Divorced/Separated & $520(8.0)$ & $63(9.8)$ & $319(63.3)$ & $138(26.9)$ & \\
\hline Never Married & $1784(25.5)$ & $301(18.9)$ & $1113(62.2)$ & $370(18.9)$ & \\
\hline Gravidity & & & & & $<0.0001$ \\
\hline 0 & $1539(28.4)$ & $240(16.0)$ & $959(63.8)$ & $340(20.2)$ & \\
\hline $1-2$ & $1973(37)$ & $116(4.3)$ & $1271(69.0)$ & $586(26.7)$ & \\
\hline $3+$ & $1666(34.6)$ & $92(3.3)$ & $1111(70.4)$ & $463(26.4)$ & \\
\hline Health insurance in the last 12 months & & & & & $<0.0001$ \\
\hline Insured continuously & $3630(71.2)$ & $345(8)$ & $2385(70.1)$ & $900(21.9)$ & \\
\hline Uninsured at some time & $1535(28.8)$ & $103(5.6)$ & $947(62.4)$ & $485(32)$ & \\
\hline \# Lifetime Sexual Partners & & & & & 0.0008 \\
\hline 1 & $1109(24.3)$ & $64(4.9)$ & $764(72.4)$ & $281(22.7)$ & \\
\hline $2-3$ & $1165(22.9)$ & $110(9.4)$ & $750(68.5)$ & $305(22.1)$ & \\
\hline $4-9$ & $1851(34.5)$ & $179(7.7)$ & $1196(67.9)$ & $476(24.5)$ & \\
\hline 10 or more & $1053(18.3)$ & $95(7.0)$ & $631(61.6)$ & $327(31.3)$ & \\
\hline \# Sexual Partners in last 12 months & & & & & 0.0045 \\
\hline 1 & $4316(86.9)$ & $302(5.8)$ & $2829(69.1)$ & $1185(25.1)$ & \\
\hline 2 & $529(8.2)$ & $94(18.9)$ & $322(58.6)$ & $113(22.5)$ & \\
\hline $3^{+}$ & $333(4.9)$ & $52(13.8)$ & $190(63.5)$ & $91(22.7)$ & \\
\hline Desires pregnancy in the future & & & & & $<0.0001$ \\
\hline Yes & $3153(55.9)$ & $321(10.1)$ & $1852(59.0)$ & $980(30.9)$ & \\
\hline No & $1892(41.3)$ & $118(3.8)$ & $1396(79.1)$ & $378(17.1)$ & \\
\hline
\end{tabular}


TABle 3: Crude and adjusted odds ratios (and 95\% confidence intervals) for dual versus non-dual-method use.

\begin{tabular}{|c|c|c|}
\hline & Crude & Adjusted \\
\hline \multicolumn{3}{|l|}{ Age } \\
\hline $15-20$ & $16.3(9.38-28.5)$ & $7.01(3.19-15.4)$ \\
\hline $21-25$ & $7.40(3.68-14.9)$ & $3.93(1.90-8.10)$ \\
\hline $26-30$ & $2.94(1.69-5.11)$ & $2.36(1.29-4.31)$ \\
\hline $31-35$ & $3.04(1.61-5.74)$ & $3.14(1.72-5.76)$ \\
\hline $36-40$ & Referent & Referent \\
\hline $41-44$ & $1.27(0.55-2.94)$ & $1.33(0.57-3.10)$ \\
\hline \multicolumn{3}{|l|}{ Race } \\
\hline Black & $1.30(0.87-1.93)$ & $0.97(0.66-1.44)$ \\
\hline White & Referent & Referent \\
\hline Others & $0.43(0.26-0.72)$ & $0.43(0.25-0.75)$ \\
\hline \multicolumn{3}{|l|}{ Ethnicity } \\
\hline Hispanic & $0.52(0.34-0.79)$ & $0.73(0.48-1.13)$ \\
\hline Non Hispanic & Referent & Referent \\
\hline \multicolumn{3}{|l|}{ Education } \\
\hline Less than HS & $1.41(0.94-2.11)$ & $0.47(0.27-0.81)$ \\
\hline High school & $\begin{array}{c}1.49 \\
(0.94-2.37)\end{array}$ & $0.94(0.55-1.58)$ \\
\hline Some college & $2.61(1.69-4.02)$ & $1.07(0.73-1.57)$ \\
\hline College graduate & Referent & Referent \\
\hline \multicolumn{3}{|l|}{ Marital status } \\
\hline Married & Referent & Referent \\
\hline Living with partner & $3.83(2.08-7.04)$ & $2.87(1.62-5.07)$ \\
\hline $\begin{array}{l}\text { Widowed/divorced/ } \\
\text { separated }\end{array}$ & $6.45(3.40-12.3)$ & $7.86(4.05-15.3)$ \\
\hline Never married & $13.9(9.32-20.8)$ & $6.45(3.62-11.5)$ \\
\hline \multicolumn{3}{|l|}{ Gravidity } \\
\hline 0 & $5.58(3.35-9.28)$ & $1.46(0.78-2.74)$ \\
\hline $1-2$ & $1.31(0.81-2.10)$ & $0.85(0.50-1.44)$ \\
\hline $3+$ & Referent & Referent \\
\hline \multicolumn{3}{|l|}{ Insurance in last 12 month } \\
\hline Insured continuously & Referent & Referent \\
\hline Uninsured at some time & $0.68(0.48-0.95)$ & $0.65(0.47-0.90)$ \\
\hline \multicolumn{3}{|l|}{ \# Lifetime sexual partners } \\
\hline 1 & Referent & Referent \\
\hline $2-3$ & $1.96(1.24-3.10)$ & $1.50(0.92-2.45)$ \\
\hline $4-9$ & $1.57(1.11-2.21)$ & $1.22(0.82-1.81)$ \\
\hline 10 or more & $1.44(0.88-2.36)$ & $1.17(0.72-1.91)$ \\
\hline \multicolumn{3}{|l|}{$\begin{array}{l}\text { Sexual partner in last } 12 \\
\text { months }\end{array}$} \\
\hline 1 & Referent & Referent \\
\hline 2 & $3.85(2.58-5.76)$ & $1.29(0.87-1.90)$ \\
\hline $3+$ & $2.57(1.60-4.14)$ & $0.81(0.48-1.36)$ \\
\hline \multicolumn{3}{|l|}{ Desires pregnancy in future } \\
\hline Yes & $2.82(1.93-4.13)$ & $0.98(0.60-1.58)$ \\
\hline No & Referent & Referent \\
\hline
\end{tabular}

and those who relied on the contraceptive vaginal ring were grouped together due to small numbers in each contraceptive subgroup. Participants who used either of the injectable contraceptives such as depot medroxyprogesterone acetate (DMPA) or combination injectable contraceptives were grouped together as "injectables." Women who used either an intrauterine device (IUD) or the contraceptive implant were grouped together as users of long-acting reversible contraceptives (LARCs). And finally, those who relied on either female or male sterilization are grouped together in the "sterilization group." In cases where respondents reported more than one contraceptive method, we chose the most effective method as defined by Trussell [12] as the primary contraceptive method. We then used this variable as a covariate in an independent multivariable logistic regression to evaluate the impact of primary method on dual-method use. All analyses were conducted in SAS (v. 9.2, SAS Institute, Cary, NC).

\section{Results}

An estimated $7.3 \%$ of US women reported dual-method use at their last intercourse in the last 12 months in the 2006-2008 NSFG. Over two-thirds of women reported a single-method of contraception and one-quarter reported no method used at the last intercourse (see Table 1). Ring users were most likely to report dual-method use with $32.6 \%$ dual use at last intercourse, whereas $21.7 \%$ of pill users, $16.7 \%$ of injectable users, and $16.0 \%$ of patch users reported dual-method use at last intercourse. Those relying on sterilization $(4.4 \%)$ or currently using a LARC method (3.3\%) were less likely to report dual-method use than women relying on less effective non-barrier contraceptive methods.

We examined the frequency of dual- and single-method use across demographic and clinical characteristics and found that rates of method use varied by age, race, ethnicity, education, marital status, pregnancy history, insurance status, and number of sexual partners (lifetime and past year; see Table 2 ). In particular, young women (15-20 years) who are at highest risk of both STI and unintended pregnancy reported the highest rates of dual-method use $(22.8 \%)$. African American women had higher rates of dual-method use $(9.4 \%)$ compared with Caucasian or Hispanic women. Education was associated with rates of dual-method use with the highest levels among women with some college education $(12.0 \%)$. Never married women were most likely to report dual-method use $(18.9 \%)$, as were nulligravid women $(16.0 \%)$. Continuously insured women were more likely to report dual-method use $(8.0 \%)$ than those with some period of no insurance (5.6\%). Dual-method use was associated with sexual history (number of lifetime sex partners or in the past year) in the unadjusted analyses. We also examined the impact of future pregnancy intention on dual-method use. We found that women who "want a pregnancy at some time" were more likely to use dualmethod protection in our unadjusted analyses.

Results of our logistic regression model are shown in Table 3. Potential confounders identified in the univariate 
TABLE 4: Association of primary contraceptive method with dualmethod use.

\begin{tabular}{|c|c|c|}
\hline Primary contraceptive method & Crude & Adjusted \\
\hline Pills & Referent & Referent \\
\hline Patch/ring & $1.40(0.68-2.89)$ & $1.15(0.61-2.19)$ \\
\hline Injectables (Lunelle/DMPA) & $0.73(0.44-1.23)$ & $0.49(0.28-0.85)$ \\
\hline LARC & $0.12(0.06-0.24)$ & $0.30(0.14-0.63)$ \\
\hline Sterilization & $0.16(0.10-0.25)$ & $0.69(0.39-1.22)$ \\
\hline
\end{tabular}

Note: controlled for age, race, ethnicity, level of education, marital status, gravidity, insurance status in the last 12 months, lifetime number of sexual partners, number of sexual partners in the last 12 months, and pregnancy intention.

analyses included age, race, ethnicity, level of education, marital status, gravidity, insurance status in the last 12 months, lifetime number of sexual partners, number of sexual partners in the last 12 months, and desire for future pregnancy. Women under the age of 36 were significantly more likely to report dual-method use compared to women in the 36-40 years age group. When compared to married women, never married women $\left(\mathrm{OR}_{\mathrm{adj}} 6.5,95 \% \mathrm{CI} 3.6-11.5\right)$ and those who were widowed/divorced/separated ( $\mathrm{OR}_{\mathrm{adj}} 7.9$, 95\% CI 4.1-15.3) had the highest likelihood of dual-method use. Lack of insurance coverage during the prior year was associated with lower rates of dual-method use $\left(\mathrm{OR}_{\mathrm{adj}} 0.7\right.$, 95\% CI 0.5-0.9) compared to women who had continuous coverage. While desire for future childbearing was associated with dual use in our bivariate analysis $(\mathrm{OR}=2.8,95 \% \mathrm{CI}$ 1.9-4.1), it was no longer significant in our logistic regression model $\left(\mathrm{OR}_{\mathrm{adj}}=1.0,95 \%\right.$ CI 0.6-1.6).

Since age and education are closely linked, we examined the results of the logistic regression model with and without age and education. Estimates of effect for age were largely unchanged by excluding education with the exception of the youngest category of women (15-20 year-olds) which was modestly attenuated.

Finally, we used a logistic regression model to examine the relationship of dual-method use by primary method of pregnancy prevention with pill users as the referent group, since pill use was the most common primary method reported (Table 4). After adjusting for all the factors associated with dual-method use from the prior adjusted analysis, women who relied on the contraceptive injection were less likely to report additional barrier use $\left(\mathrm{OR}_{\mathrm{adj}} 0.5\right.$, 95\% CI 0.3-0.9). LARC users were significantly less likely to report dual-method use $\left(\mathrm{OR}_{\text {adj }} 0.3,95 \%\right.$ CI 0.1-0.6). There was no statistically significant difference in the likelihood of dual use in male or female sterilization and patch/ring users compared to pill users.

\section{Discussion}

Our analysis indicated $7.3 \%$ of reproductive-aged women at risk for both pregnancy and STIs in this nationally representative sample reported using dual-method protection at last intercourse. Increased dual-method contraceptive use was associated with younger age and not being married, but inversely associated with gaps in insurance coverage. A statistically significant lower rate of dual-method use was noted in women relying on the most effective forms of reversible pregnancy prevention: DMPA and LARC methods.

The 7.3\% overall rate of dual-method use among the whole sample is consistent with previously published reports $[6,7]$. It is encouraging to note the higher rate of dualmethod use among teenagers and those under age 25 in this analysis as they have the highest incidence of STIs and unintended pregnancy. Sieving et al. noted a higher rate of two methods of contraception being used at most recent intercourse among older teens versus younger teens [8]. We found $22.8 \%$ of $15-20$-year olds and $12 \%$ of $21-25$-year olds reported dual-method protection. In a sample of women using LARC methods, Pazol et al. noted that high-school graduates were more likely than those without a high-school diploma to report condom use at last intercourse [13]. This is also consistent with our finding that higher educational levels are associated with dual-method use.

Few studies have evaluated factors associated with dualmethod use. One study of adolescent girls noted that the strongest correlate of dual-method use was a desire to avoid pregnancy [14]. Impulsivity, self-esteem, social support, relationship status, partner communication, fear of condom negotiation, and desire to avoid unintended pregnancy have been associated with dual-method use among adolescents $[14,15]$.

Our finding of a positive association of dual-method use among respondents who are not currently married compared to married women is not surprising. Married women likely perceive less risk of STI acquisition and unintended pregnancy. This is consistent with other reports of lower rates of condom use among married women [4]. The lower rate of dual-method use reported among women who had a gap in insurance coverage during the past 12 months is likely due to limited access to prescription contraceptive methods or interruptions in continuity of care during these periods [16].

There is concern that women relying on LARC methods may have lower rates of barrier method use. Pazol et al. examined NSFG data from 2002-2003 and found that only $1.9 \%$ (95\% CI 0.0-4.0) of respondents who reported using LARC methods also used a condom at last intercourse [13]. Our analysis also noted lower rates of dual-method use in women using LARC methods and DMPA. This lower rate may be due to these women feeling reassured that they have a highly effective contraceptive method and not recognizing their continued risk of STI acquisition.

A major strength of our study is that this data represents a national sample of reproductive-aged which reflects the experiences of approximately 44.5 million women in the United States. Our findings are more generalizable than studies that focus on adolescents or clinic-based samples. Our sample size provided sufficiently large numbers to assess differences in dual-method use across many exposure categories. However, there are some limitations of this analysis. Our estimate of 7\% dual-method use may be a slight underestimate, as there are some women in the denominator of this analysis that may not be using dual methods or any 
contraception due to a desire to conceive. Data regarding current contraceptive method was based on the respondents' reports of contraception at last intercourse which may be affected by both difficulty with recall and social desirability issues. It is difficult to extrapolate dual-method contraceptive use at last intercourse to dual use as a regularly practiced behavior. Additionally, the low number of women reporting using LARC, the patch, or ring for contraception reduces the level of precision of our estimates and makes it difficult to draw conclusions regarding women using these methods. Ideally, we would have liked to have examined other markers of high-risk sexual activity, such as a history of abortion or sexually transmitted infection, but we were limited by questions included in the NSFG survey and underreporting of abortions [17].

\section{Conclusions}

A small proportion of women who are at risk for unintended pregnancy and STIs use dual-method protection. We believe the findings from this study can be used to inform interventions to improve dual-method use. It is our hope that there will be increased access to prescription contraceptive methods due to the Department of Health and Human Services recommendations for contraceptive coverage [18]. This could alleviate the gaps in insurance coverage which we found to be associated with decreased rates of dual-method use. Our findings of the lowest rates of barrier use among users of the most effective reversible contraceptives (LARC methods and DMPA) suggest that women using these methods are an important group for intervention development to promote dual-method use. A comprehensive approach to educating women about risk factors for unintended pregnancy and STI acquisition along with methods of prevention is essential.

\section{Acknowledgments}

This research was supported in part by a Midcareer Investigator Award in Women's Health Research (K24 HD01298), by a Clinical and Translational Science Award (UL1RR024992), and by Grant no. KL2RR024994 from the National Center for Research Resources (NCRR), a component of the National Institutes of Health (NIH) and NIH Roadmap for Medical Research. Its contents are solely the responsibility of the authors and do not necessarily represent the official view of NCRR or NIH. Information on NCRR is available at http://www.ncrr.nih.gov/. Information on Reengineering the Clinical Research Enterprise can be obtained from http://nihroadmap.nih.gov/clinicalresearch/overviewtranslational.asp.

\section{References}

[1] H. Weinstock, S. Berman, and W. Cates Jr., "Sexually transmitted diseases among American youth: incidence and prevalence estimates, 2000," Perspectives on Sexual and Reproductive Health, vol. 36, no. 1, pp. 6-10, 2004.
[2] H. W. Chesson, J. M. Blandford, T. L. Gift, G. Tao, and K. L. Irwin, "The estimated direct medical cost of sexually transmitted diseases among American youth, 2000," Perspectives on Sexual and Reproductive Health, vol. 36, no. 1, pp. 11-19, 2004.

[3] L. B. Finer and S. K. Henshaw, "Disparities in rates of unintended pregnancy in the United States, 1994 and 2001," Perspectives on Sexual and Reproductive Health, vol. 38, no. 2, pp. 90-96, 2006.

[4] W. D. Mosher and J. Jones, "Use of contraception in the United States: 1982-2008. National Center for Health Statistics," Vital and Health Statistics. Series 23, no. 29, 2010.

[5] CDC, Sexually Transmitted Disease Surveillance 2009, Centers for Disease Control and Prevention, Atlanta, Ga, USA, 2010.

[6] J. S. Santelli, C. W. Warren, R. Lowry et al., "The use of condoms with other contraceptive methods among young men and women," Family Planning Perspectives, vol. 29, no. 6, pp. 261-267, 1997.

[7] J. E. Anderson, J. Santelli, and B. C. Gilbert, "Adolescent dual use of condoms and hormonal contraception: trends and correlates 1991-2001," Sexually Transmitted Diseases, vol. 30, no. 9, pp. 719-722, 2003.

[8] R. E. Sieving, L. H. Bearinger, M. D. Resnick, S. Pettingell, and C. Skay, "Adolescent dual method use: relevant attitudes, normative beliefs and self-efficacy," Journal of Adolescent Health, vol. 40, no. 3, pp. 275-e15-22, 2007.

[9] J. M. Lepkowski, W. D. Mosher, K. E. Davis, R. M. Groves, and J. Van Hoewyk, "The 2006-2010 National Survey of Family Growth: sample design and analysis of a continuous survey," Vital and Health Statistics. Series 2, no. 150, pp. 1-36, 2010.

[10] W. D. Mosher and J. Jones, "Use of contraception in the United States: 1982-2008," Vital and Health Statistics. Series 23, no. 29, pp. 1-51, 2010.

[11] CDC, 2006-2010 NSFG Codebooks, Centers for Disease Control and Prevention, Atlanta, Ga, USA, 2011, http://www.cdc .gov/nchs/nsfg/nsfg_2006_2010_codebooks.htm/.

[12] J. Trussell, "Contraceptive failure in the United States," Contraception, vol. 70, no. 2, pp. 89-96, 2004.

[13] K. Pazol, M. R. Kramer, and C. J. Hogue, "Condoms for dual protection: patterns of use with highly effective contraceptive methods," Public Health Reports, vol. 125, no. 2, pp. 208-217, 2010.

[14] R. A. Crosby, R. J. DiClemente, G. M. Wingood et al., "Correlates of using dual methods for sexually transmitted diseases and pregnancy prevention among high-risk africanamerican female teens," Journal of Adolescent Health, vol. 28, no. 5, pp. 410-414, 2001.

[15] J. M. Sales, T. P. Latham, R. J. DiClemente, and E. Rose, "Differences between dual-method and non-dual-method protection use in a sample of young African American women residing in the Southeastern United States," Archives of Pediatrics and Adolescent Medicine, vol. 164, no. 12, pp. 11251131, 2010.

[16] K. R. Culwell and J. Feinglass, "The association of health insurance with use of prescription contraceptives," Perspectives on Sexual and Reproductive Health, vol. 39, no. 4, pp. 226-230, 2007.

[17] R. K. Jones and K. Kost, "Underreporting of induced and spontaneous abortion in the United States: an analysis of the 2002 National Survey of Family Growth," Studies in Family Planning, vol. 38, no. 3, pp. 187-197, 2007.

[18] R. Pear, "Insurance coverage for contraception is required," New York Times, 2011. 


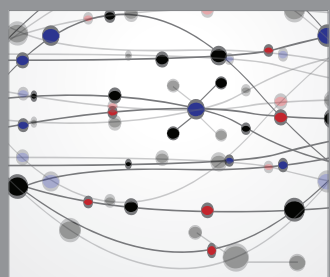

The Scientific World Journal
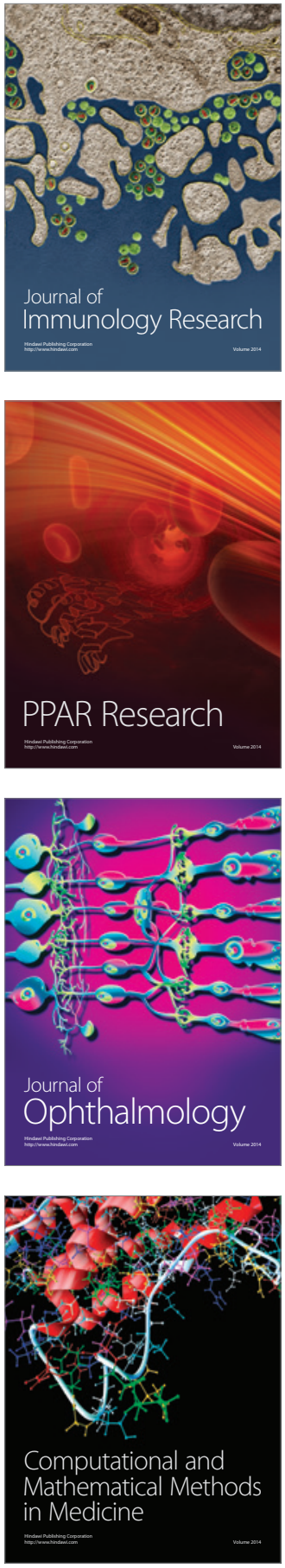

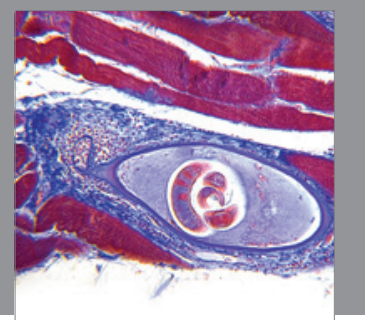

Gastroenterology

Research and Practice
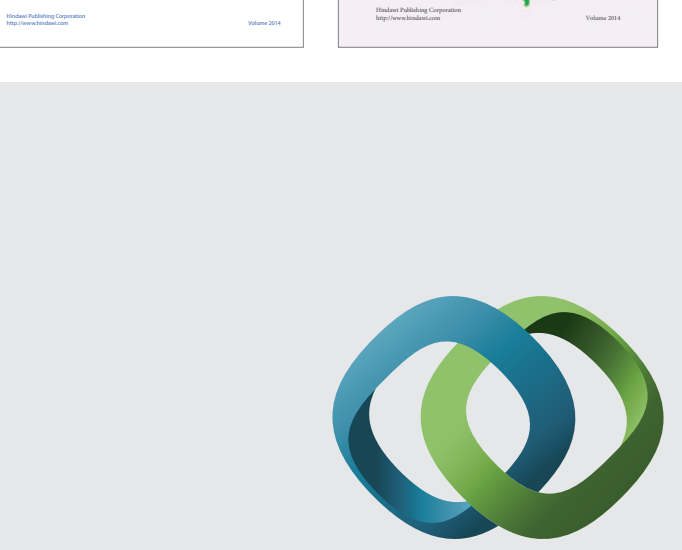

\section{Hindawi}

Submit your manuscripts at

http://www.hindawi.com
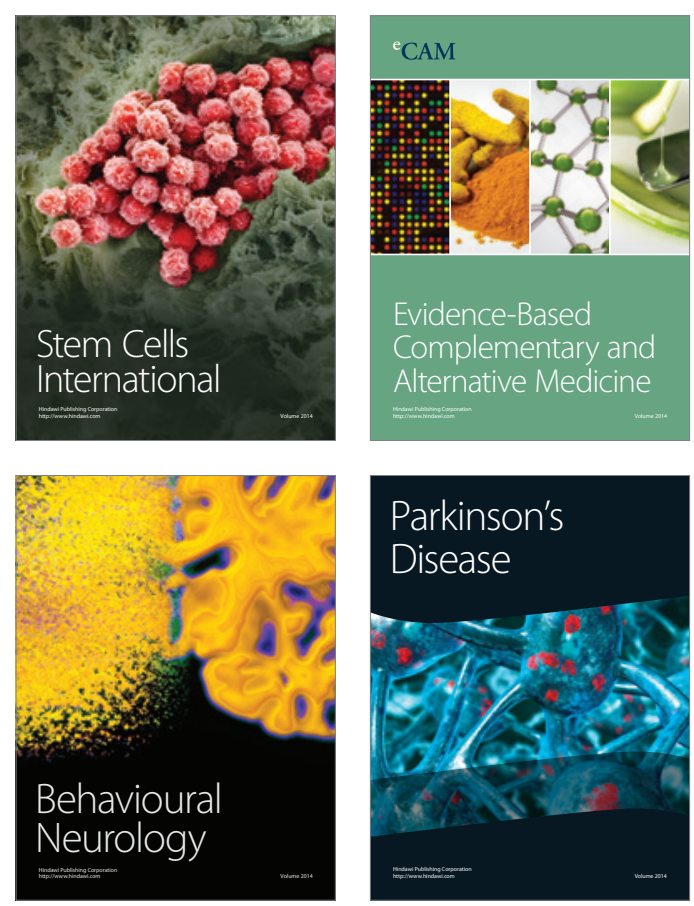

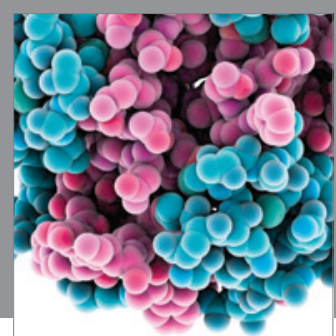

Journal of
Diabetes Research

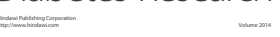

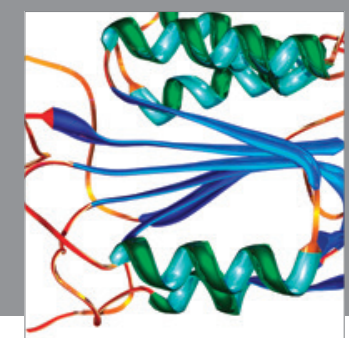

Disease Markers
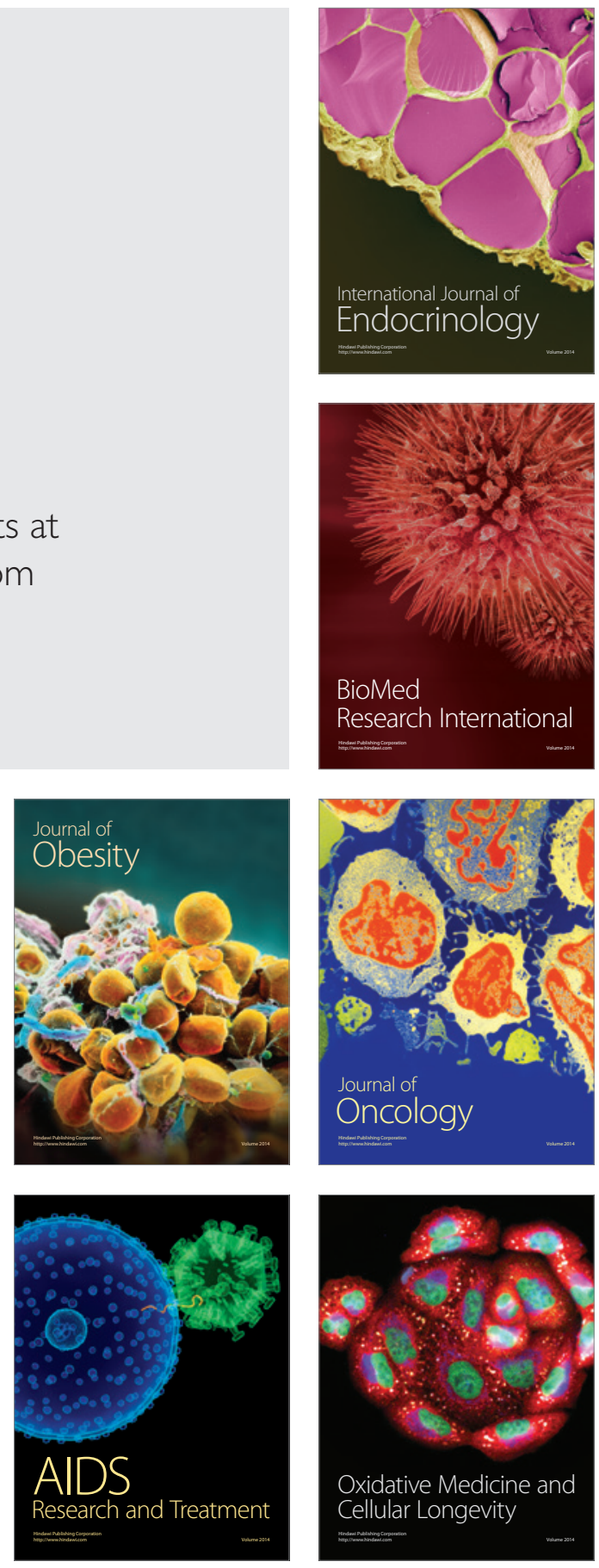